\title{
Happiness and relational goods: well-being and interpersonal relations in the economic sphere
}

\author{
Benedetto Gui • Luca Stanca
}

Published online: 18 May 2010

(C) Springer-Verlag 2010

\begin{abstract}
The present paper provides an introduction to this special issue devoted to Happiness and Relational Goods. We start by presenting a few concepts that have recently appeared in the economic literature with the aim of capturing some of the peculiarities of personalised interactions. We claim that these concepts can be subsumed fairly well under the concept of 'relational goods'. We then review the recent empirical literature on happiness and relational goods. Finally, we briefly introduce the papers contained in this special issue by outlining their respective contributions.
\end{abstract}

"The main things which seem to me important on their own account, and not merely as means to other things, are knowledge, art, instinctive happiness, and relations of friendship or affection"

(Bertrand Russell)

\section{Introduction}

"No Man is an Island". It is not by chance that it is two economists, and not students of another social science, who have recently chosen this statement, taken from John Donne' Meditation XVII, as the title of a scientific paper (Aslam and Corrado 2007). Indeed the Walrasian description of society, on which so much of economic theory has been based, is precisely an archipelago of one-man islands, connected by an

\footnotetext{
B. Gui $(\bowtie)$

Department of Economic Sciences, Via del Santo 33, 35123 Padova, Italy

e-mail: benedetto.gui@unipd.it

L. Stanca

Economics Department, University of Milan-Bicocca, Piazza dell'Ateneo Nuovo 1,

20126 Milan, Italy

e-mail: luca.stanca@unimib.it
} 
(unmanned) boat service for the transportation of standardised messages and the merchandises exchanged.

Surely, since Walras' times much water has flown under the bridges. In fact, not only do contemporary economic models deal with largely imperfect markets in which the parties meet face-to-face for communicating, bargaining, cheating, ... Economics has also increasingly considered various forms of non-market influences: your tax evasion makes mine more likely to remain undetected; your prestigious possessions reduce the pride I take from my possessions; by observing your career choices I derive information that is useful for guiding mine; and so on. Many more examples can be found in the social interactions literature (see e.g. Durlauf and Ioannides 2010). Still, the re-socialisation of economic interactions that is under way in economics has largely left aside their truly interpersonal side. In most accounts of economic life, this crucial isthmus between individual territories is missing; so contemporary economic agents, if not islands, are still peninsulas. But what is it meant exactly, by interpersonal side of economic interaction?

Answering this question is neither easy nor uncontroversial. We thus turn for help to the recent economic literature. A few novel notions-novel for economic analysis - are of interest in this regard, as each captures part of what we are searching for. We briefly present them in Sect. 2. The section ends with relational goods. This notion - one that both of us have dealt with in our research work-lends itself fairly well to be used as a catchphrase for all of the above. In Sect. 3, we focus instead on happiness, the other keyword of the title of this special issue, and on the empirical links between the two. Finally, in Sect. 4, we briefly introduce the papers contained in this special issue and outline their respective contributions. ${ }^{1}$

\section{Theoretical insights into the interpersonal side of economic interactions}

\subsection{Some useful concepts}

The first concept that can help our exploration is social engagement, that is the very fact of being involved in personalised interactions on a regular basis (see Gui and Sugden 2005). Social engagement generates both intrinsic and instrumental benefits. $^{2}$ These are reaped at the same time by several beneficiaries, which make social engagement a public good, potentially liable to underprovision. ${ }^{3}$ This is often the actual outcome in modern societies, as technological advancements have unbundled social engagement from other goods, the enjoyment of which used to

\footnotetext{
1 The papers presented in this special issue were presented in a preliminary version at the conference Happiness and relational goods: Well-Being and Interpersonal Relations in the Economic Sphere, held in Venice in June 2009. The conference was jointly organized by the Department of Economic Sciences of the University of Padova, the Department of Economics of the University of Milan Bicocca, the association HEIRs, and the research centres EconomEtica and CISEPS. We thank these institutions and the Federation of Cooperative Banks of the Veneto Region for the support received.

2 Feelings of belonging and access to information are obvious examples.

3 Showing up at the right moment is costly, at least some of the times (the more so, the higher the opportunity cost of time for potential participants).
} 
ensure participation (an example is the replacement of the hot meal prepared for the whole family at the agreed time by pre-cooked individual food servings to be heated at will in microwave ovens). ${ }^{4}$ On the other hand, securing social engagement through markets, rather than as a side product of other activities, is not fully satisfactory, since a condition for its granting intrinsic benefits is genuineness: a property most likely to be lost if the behaviour of one party is dictated by a contract.

Other concepts are aimed at capturing part of what happens within or through personalised interactions. Robert Dur and coauthors (Dur 2009; Dur and Roelfsema 2010; Dur and Sol 2009) introduce in their models the notion of attention. With this expression they refer to the 'socioemotional resources' that a manager or a colleague devotes to a worker (Dur 2009, p. 551). Attention, as a deliberate act of listening and caring, is costly to the giver and is beneficial to the receiver. Peculiar features of attention are non-contractibility and the need for personal involvement of the giver: valuable attention can only be awarded in real interactions (so one has to look for evidence in the field, rather than the lab).

A similar concept, proposed a few years earlier by Avner Offer (1997), is regard. "Regard is an attitude of approbation" (p. 452) that is communicated primarily, albeit not exclusively, in face-to-face settings. ${ }^{5}$ Regard is also a source of satisfaction, one of the "intrinsic benefits of social and personal interaction". 6 Something alike is also contained is Brennan and Pettit's (2004) esteem. First of all, differently from other goods we obtain from others as an effect of their actions (think of a repair service), esteem "come[s] into being by virtue of what people think and feel about the person esteemed; that is, by virtue of their attitudes" (p. 2). Second, although esteem can be awarded by unknown people, we care mostly about the esteem of those who are closest to us. And while not everybody can enjoy it thanks to spectacular performances, still everybody can have access to at least one of the components of esteem, recognition as a person worthy of attention and respect (see in particular Chap. 10), on the condition that relatives, friends or colleagues are disposed to grant it (typically in personalised interactions).

Another concept that has been proposed in the attempt at capturing some of the elusive ingredients of the truly interpersonal dimension of human interaction is socio-emotional goods. By this expression Robison et al. (2002) refer to those (typically intangible) entities that are capable of satisfying socio-emotional needs (see Maslow (1962). According to these authors, such goods include "expressions serving to validate one's usefulness and importance" and "information flows communicating encouragement, support, and acceptance" (p. 18), both of which are characteristic of face-to-face situations (see also Robison and Flora 2003). All this brings us close to Offer's regard, or Brennan and Pettit's recognition.

Indeed, in personalised interactions-included those that occur within the economic domain-communication at the level of attitudes and emotions plays a

\footnotetext{
${ }^{4}$ Another example is the possibility to enjoy music, not in crowded concert halls, but with personal MP3players.

5 As to how regard is communicated Offer observes: "Language is a vehicle of regard, and conversation is ... loaded with cues of acceptance or disdain" (p. 454).

6 As to the similarity between attention and regard, Offer writes: “At the very least, 'regard' is a grant of attention" (p. 450)—indeed a scarce resource..
} 
crucial role. This is underlined by students of service marketing. An interesting reference is Chase and Dasu (2008), who observe that "[t]he heart of a service is the encounter between the server and the customer", and complain that the significance of emotions has been systematically neglected so far (p. 36). Although these scholars only seem to care about the effects on the organisation's ability to attract and retain customers, the quality of interpersonal communication in service-related interactions affects not only customers but also service personnel. We will return to this point, but notice with Robison et al. (ibidem) that, depending on attitudes, personalised interactions have the potential for creating a surplus for the parties involved.

A peculiar aspect of interpersonal phenomena that has not yet come to light, is their entailing two-way affective communication, or, to be more precise, a two-way interaction at the level of sentiments and emotions. This peculiarity is an essential feature of the correspondence of sentiments, an even more innovative notion for economics than those discussed so far. The proposer is Robert Sugden, who starts from a re-examination of the Smithian notion of fellow feeling, that is "one person's lively consciousness of some affective state of another person" (2002, p. 71). The truly interpersonal phenomenon here is the mutual awareness of the correspondence of one's sentiments with those of others; and a pleasant one, as it reinforces the feelings of being supported, when one is in grief, and enhances the enjoyment, when one lives an agreeable situation. The correspondence of sentiments-Sugden observes-is one of the mechanisms through which "social relations have subjective value for human beings" (p. 63); but this mechanism is entirely extraneous to the traditional economic approach to human interactions, since "fellow-feeling does not fit into the ontological framework of rational choice theory". 7

Nothing has been said so far as to the flow-versus-stock nature of the features of personalised interactions being discussed. Some authors-among them Frans Van Winden ${ }^{8}$ - study social ties, affective bonds among particular individuals. Social ties are created through prolonged interaction, and evolve as a function of how these interactions unfold: they strengthen when counterparts' actions are perceived as beneficial or nice, and loosen instead when counterparts' actions appear as harmful or unkind. The first models developed so far operationalise them simply as altruism parameters whose dynamics are driven by the payoffs of past rounds of a repeated game. However, the notion of social ties captures the idea that in interpersonal relationships, intangible relation-specific stocks of capital goods are at play, and that these have an affective component.

\subsection{Relational goods}

The concept of relational goods makes its first appearance in an international economic journal in 1989 by the agency of Carole Uhlaner. She has in mind as her primary example those intangible outcomes_-such as a sense of belonging to a

\footnotetext{
7 In fact, he later explains, "the only mental attitudes that rational choice theory admits are preferences (and, in the presence of uncertainty, beliefs)" (p. 69). See also Sugden (2005a, b).

8 See among other papers: Sonnemans et al. (2006), Van Winden et al. (2008).
} 
group - that people obtain from active political participation. Other authors have later developed on this notion (see among others: Bruni 2008; Pugno 2009; Sacco et al. 2006). Despite differences among them, it is agreed that relational goods spring out of interpersonal relationships, as a function of who the people involved are (personalisation), and of what they do, prefer, and feel (in particular, reciprocity of actions and attitudes matter, and non-contractibility prevails); and, therefore, that relational goods are simultaneously created and consumed by interacting parties.

The ability of the notion of relational goods to capture fairly well the richness of the interpersonal phenomena discussed so far is enhanced by Gui's (2005) proposal to view interpersonal events as 'encounters': peculiar productive processes that employ various types of resources contributed by interacting parties (human resources, above all), and that deliver not only conventional outputs (such as exchange agreements, the provision of services, or the accomplishment of productive tasks by teams,...) but also relational outputs. The latter can be distinguished into: a flow of 'relational consumption goods', such as 'company', 'recognition', 'entertainment' (without excluding 'relational consumption bads'); and accumulation of 'relational capital goods' (or, more simply, relation-specific capital), made partly of 'local information' concerning fellow interacting parties, and partly of affective bonds (e.g. feelings of friendship). ${ }^{9}$ Needless to say, the relational outputs obtained are a function-surely a complex one-of the number, characteristics, time and effort contributed, and attitudes, of interacting parties; in addition, they are also affected by the surrounding social and physical environment.

This framework has been developed with primary reference to encounters taking place within productive organisations or at their interfaces with counterparts in transactions. However, it lends itself to also analysing interpersonal relationships within families, informal social groups, or associations. Here the 'conventional output' to be taken into consideration may be, for instance: a home meal, the completion of a mountain hike, or the performance of an amateur music band. But the process of generation of relational outputs is basically the same.

\section{Happiness and interpersonal relationships}

Research on happiness is at a more mature stage than the economics of interpersonal relationships. So there is no need to discuss its definitions in detail. The principal acceptations of happiness that are used in the recent social science literature are three: (i) feelings of joy and pleasure (that psychologists call positive affect); (ii) overall contentment with life (or life satisfaction); and (iii) the quality of life achieved by fulfilling one's potential (or 'eudaimonia'). ${ }^{10}$ While the third definition is hard to translate into observable variables, definitions (i) and (ii) lend themselves reasonably well to empirical research, and in particular to measurement through

\footnotetext{
${ }^{9}$ Here too one must consider the possibility that interacting parties develop, instead, hard feelings, such as hatred, towards each other. This can be viewed as a decumulation of relation-specific capital. Observe that the updated stock of 'relational capital goods' will be available for use in further encounters with the same counterparts.

${ }^{10}$ See for instance Frey (2008, p. 5).
} 
questionnaires. The rich strand of literature that has exploited such opportunity has intensely investigated the impact on people's subjective well-being (SWB) of a wide array of possible determinants. This has opened the way for studying at the empirical level how individuals make choices concerning interpersonal relationships, and the links between such choices, economic behaviour and individual outcomes. Indeed, until very recently little was known about all this, and economic investigations of relational goods (and similar entities) seemed unable to move beyond armchair theorising.

In fact, outside economics, applied social scientists have long identified social relationships as a key determinant of well-being. In psychology, there is extensive evidence about the links between interpersonal relationships and happiness (e.g. Deci and Ryan 1991; Baumeister and Leary 1995; Kahneman et al. 2004). Within the eudaimonic approach, in particular, many authors have identified a fundamental association between the quality of relationships and well-being (e.g. Argyle 2001; Myers 1999; Deci and Ryan 2001). Research on intimacy has also highlighted the importance of relatedness for well-being and underlined the relevance of the quality of relatedness for well-being (e.g. Kasser and Ryan 1999; Ryff and Singer 2000).

Within economics, instead, interpersonal relations have received attention mainly as one of the constituent elements of social capital, a multi-dimensional concept that identifies " $[\cdots]$ features of social organisation, such as trust, norms, and networks that can improve the efficiency of society by facilitating coordinated actions" (Putnam 1993, p. 167). Social capital is a concept that includes rather heterogeneous dimensions. As observed by Dasgupta (2002, p. 5), "[Social capital] encourages us to amalgamate incommensurable objects, namely (and in that order), beliefs, behavioural rules, and such forms of capital assets as interpersonal links, without offering a hint as to how they are to be amalgamated".

A large number of studies have investigated empirically the measurement of social capital (e.g. Grootaert and van Bastelaer 2002; Bjornskov 2007) and its effects on economic performance (e.g. Guiso et al. 2000; Routledge and von Amsberg 2002) and well-being (e.g. Bjornskov 2003; Haller and Hadler 2006; Aslam and Corrado 2007). This literature, however, has focused mainly on aspects such as trust, social norms and associational activity, emphasising the instrumental value of informal connections among the members of social groups in facilitating coordinated action. Instead, personalised relationships and their intrinsic value for people involved have been largely disregarded. Lack of specific empirical evidence and the difficulty of obtaining information on the subtle issues that characterise human interaction have certainly contributed to this state of affairs.

This is why research on happiness has revealed itself so crucial for the empirical assessment of the role of relational goods. Two main groups of studies can be identified within the empirical literature on happiness and interpersonal relationships. The first aims at assessing the relevance of relational goods for individual well-being, thus providing evidence for an explanation of the Easterlin paradox that is based on diminished consumption of relational goods. The second, relatively smaller, group aims at valuing interpersonal relationships by using implicit prices derived from the estimation of well-being equations. In the rest of this section, we briefly review the most recent contributions from these two strands of literature. 


\subsection{The relational treadmill}

In the past decades, following the seminal contribution by Easterlin (1974), a large number of studies have investigated the relationship between income and happiness, providing evidence for the so-called Easterlin paradox. This expression refers to the finding that, although better economic conditions are generally associated with higher SWB across individuals and countries, happiness does not increase with income over time. In particular, countries characterised by relatively high growth rates of GDP per capita have not displayed corresponding increases in well-being.

The main explanations for this evidence are based on the roles played by adaptation, aspirations and social comparison (Kahneman 1999; Frank 2000; Frey and Stutzer 2002; Layard 2005). The hedonic treadmill (Brickman and Campbell 1971), refers to the idea that well-being may remain unchanged, despite higher material achievements, because of fast adaptation. The satisfaction treadmill refers to the idea that SWB may not increase as income rises if aspirations rise at the same time. The positional treadmill refers to the idea that utility depends on relative consumption, rather than its absolute level, so that an individual's well-being may be unaffected by a rise in her own income if the income of others in her reference group also rises. All these explanations of the Easterlin paradox do not consider a direct link between interpersonal relations and individual well-being, as they do not view the former as a source of happiness per se. Positional theories, in particular, are based on social comparison, but this kind of interdependence has no reference to the genuinely relational nature of happiness.

More recently, a relational explanation has been proposed for the Easterlin paradox: a lower quantity and quality of interpersonal relationships may contribute to offset the impact of better economic conditions on well-being (e.g. Lane 2001). As a society becomes more affluent, the effect of improved economic conditions on individual happiness is counterbalanced by a lower quality of relational life. This mechanism can be interpreted as a relational treadmill, that operates in addition to the hedonic, satisfaction and positional treadmills. The possible existence of a causal link between material and relational conditions is effectively described by Diwan (2000, p. 305): "Our human and national welfare depends on both material and relational wealth $[\cdots]$. There is a tension between material and relational wealth. As material wealth increases beyond a certain level, it impinges on relational wealth. Our current economic practices and policies concentrate on the maximisation of material wealth only with minimal concern for its negative effects."

At the empirical level, a number of recent studies have investigated the relationship between relational goods and happiness. Bruni and Stanca (2008), who work on a large sample of individuals from the World Values Survey, use as proxies of relational goods two separate sets of indicators that closely embody the features of identity and genuineness that characterise them. Their findings indicate that the relational component of volunteering is positively and significantly associated with higher life satisfaction: in particular, the effect of active participation in voluntary organisations (over and above pure membership) is quantitatively similar to that of moving up by one decile in the income scale. Interestingly, those voluntary activities where the dimension of genuineness (non-instrumentality) is strongest, 
such as charity, church, and art-related activities, matter most for life satisfaction. Time spent in relational activities also has a large positive effect on life satisfaction. This holds in particular as to time spent with parents and relatives comes first, and also, to a smaller extent, as to time spent with friends and with people at voluntary organisations. Instead, relational activities where the identity of the individual is less relevant, such as time spent with work colleagues or members of one's own church, are not significantly related to life satisfaction. That relational goods have a large and significant positive effect on life satisfaction is confirmed by Becchetti et al. (2009a), a closely related study. Another result is that television viewing plays a significant role in explaining underconsumption of relational goods (see also Bruni and Stanca 2006, on the role played by television for the aspiration treadmill).

Becchetti et al. (2008) also investigate the impact of sociality on individual wellbeing, testing the hypothesis that people with a more intense relational life are happier. Their findings indicate that relational activities have significant and positive effects on self-reported life satisfaction, even when reverse causality is explicitly taken into account. Their study also indicates that the effects of relational goods on happiness are stronger for women, and for older and less educated individuals. Becchetti et al. (2009b) also provide an attempt to establish the causal direction of the link between sociality and well-being, using compulsory retirement as a source of exogenous variation. They find that, although the causal link is bi-directional, the effect of sociality on well-being is predominant.

\subsection{Relational goods quantified}

Data on self-reported well-being have been used increasingly in recent years to value goods that do not have a monetary price, thus providing important indications for public policy (see Van Praag and Ferrer-i-Carbonell 2004, Frey et al. 2004, and Di Tella and MacCulloch 2006, for a discussion). Subjective assessments of wellbeing have been used as a proxy measure for utility in order to estimate the monetary value of a wide range of environmental and social factors, such as pollution, terrorism, and chronic diseases. The so-called Life Satisfaction Approach (Frey 2008) has become widely accepted as an alternative to the traditional methods of preference measurement based on contingent valuation or revealed preferences.

A similar approach has also been used recently to value interpersonal relationships. Clark and Oswald (2002) have used happiness surveys to estimate the monetary value of different life events. They find in particular that marriage produces each year the same happiness as having an extra income of $£ 70,000$ per annum, while widowhood would have to be compensated by an extra income of $£ 170,000$ per annum. Powdthavee (2008) has applied a similar shadow pricing method to individual data from the British Household Panel Survey, in order to estimate the monetary value of interactions with friends, relatives and neighbours. His findings indicate that interactions with friends and relatives can be attributed to a large and significant monetary value.

More recently, Stanca (2009) has proposed a method for the measurement of the quality of relational life based on implicit valuations estimated from microeconometric life-satisfaction equations. These implicit prices are used to weigh and 
aggregate scores on several dimensions of relational life, which enables to construct indicators that focus on three dimensions of interpersonal relations: friends, family, and society. These indicators are used, in turn, to compare the quality of relational life across countries throughout the world and to explore its determinants at both individual and country level. The results indicate that across individuals, ceteris paribus, better economic conditions are associated with higher quality of interpersonal relationships.

Overall, the recent empirical literature on happiness and relational goods has provided stimulating results. The general finding is that interpersonal relationships have a large and significant effect on well-being. Furthermore, and perhaps more importantly, it is the relationships and activities where the dimensions of genuineness and identity are stronger, that matter most for life satisfaction and happiness. These results are consistent with an explanation of the Easterlin paradox based on the relational treadmill hypothesis, although there is no evidence of a negative causal link between economic conditions and quality of relational life.

\section{Contributed papers}

In the first paper of this special issue, Corneo (2010) develops a theoretical model of the formation of cultural values regarding economic achievements, on the one hand, and, nationalism, on the other. Individual utility functions include a term expressing the quality of interpersonal relations. This depends on the degree of approbation the individual obtains from others, which in turn-especially at the first, crucial, encounter-depends on her observable characteristics. It is here that the values people have been taught enter into play, as they determine the approbation or disapprobation they will express towards their partners in (random) encounters. The model is closed by parents' choice of the values to be instilled into their children, which is made according to the criterion of maximum utility for the latter. The author obtains that xenophobia is likely to be highest at intermediate levels of innate ability, and finds a confirmation of this claim in an econometric exploration based on three databases. What this paper adds to the literature on relational goods is an explicit consideration of the effects that are exerted on encounters by a component of interactants' human capital that is category- (not relation-) specific: preconceptions regarding the observable traits of the other interacting parties.

The second paper, by Magliulo (2010), looks back into the history of economic thought so as to help contemporary students of interpersonal relationships understand more clearly why mainstream economics has ended up locating this topic outside its domain of inquiry. Indeed, almost 140 years ago Menger confronts openly the question whether relationships of "friendships and love, religious fellowships, and the like" are to be considered economic goods. Ten years later Böhm-Bawerk goes as far as to use the expression 'relationship-goods'. Both authors think that these are indeed economic goods, but can be subsumed into the broader category of 'useful services'. In his last writing on the subject, however, Menger finds the interpersonal relationships lack the condition of 'availability', so they are left to the care of other social sciences. The paper also discusses the 
viewpoints of Wicksteed and Robbins, documenting — among other things - that the latter author, who has codified 20th century's economic methodology, had in fact left some space for human relationships within economics. The author concludes by stating that the crucial condition that justifies the expression relational goods is the presence of an opportunity cost.

Next come four papers that investigate at the empirical level the links between interpersonal relations and subjective well-being (SWB). DeLeire and Kalil (2010) examine the relationship between happiness and eight categories of consumption expenditure, using data from a sample of 1,700 retired Americans. They find that only one category-expenditure on leisure-is significantly associated with SWB. At first sight, their results seem to suggest that consumption of conventional goods 'does not buy happiness'. However, another interpretation is possible: that consumption expenditure 'can buy happiness', but this effect is not independent of what people choose. Next the authors raise the question whether the effect of leisure consumption on happiness is mediated by social connectedness (measured by loneliness and embeddedness in social networks), and find a confirmation of this hypothesis. Interestingly, this seems to imply that conventional goods can be considered intermediate goods rather than final goods. Last, their results corroborate the evidence that social involvement boosts SWB.

Bünger (2010) presents an empirical investigation of the determinants of meeting friends and of the effects relational activities exert on well-being. Based on a large sample of individuals from the European Social Survey, the author obtains a rich set of results. In accordance with the literature, he finds that the frequency of social contacts is significantly and positively associated with happiness. However, his main finding is that the demand for relational goods in European countries is not negatively related to the opportunity cost of time, measured by the wage rate. Similarly, he also finds that income is positively related to the frequency of social contacts, and that this holds both at individual and country level. Overall, these results indicate that, consistently with the findings in Stanca (2009), the consumption of relational goods is positively related to economic conditions. Does this mean that the income effect more than offsets the substitution effect, at least in cross-sections? This is an important question that should be addressed in future research.

Bartolini and Bilancini (2010) investigate the role of interpersonal relationships as a determinant of well-being. After summarising the evidence indicating that in the long-run income is not a good predictor of SWB, they discuss if and to what extent sociability can represent a valid alternative. In doing so, they review a small strand of empirical literature to which they have importantly contributed. The evidence available includes both within-country and world-wide level data. The former refers to the United States (where indexes of sociability have decreased) and Germany (where these indexes have increased). The analysis indicates that the evolution of consumption of relational goods plays a key role in explaining the long term dynamics of subjective well-being. Their conclusion is that economic prosperity can favour SWB, provided it does not entail a decline in sociability.

Zappa and Zavarrone (2010) present an empirical investigation of volunteer satisfaction, using questionnaire data containing information about the interpersonal 
relations characterising their volunteering activity. The interviewees operate in an Italian non-profit organisation that provides primary healthcare. The authors' methodology is based on social network analysis and exploits information about the ties each interviewee declares to have with fellow volunteers, distinguishing between co-working ties and solidarity (or friendship) ties. They test various hypotheses concerning the impact on a volunteer (multidimensional) satisfaction of her position in the network of co-workers. Although the sample size is small, the insight into their analysis is not. The key finding is that features such as receiving recognition for one's contribution or being involved in decision processes seems to matter more for volunteer's satisfaction than friendship ties with fellow volunteers. The authors observe that their results depict volunteers as having somewhat similar attitudes to ordinary workers and suggest that this may depend on the fact that, in the context under exam, they operate within a hierarchical organisational structure that is not often found in volunteer activities.

Finally, Nelson (2010) examines the 'happiness and interpersonal relations' research programme from the viewpoint of feminist economics. This has long criticised some features of mainstream economics - in particular its nearly exclusive focus on self-interest, autonomy, rationality, and exchange relations - as the product of a masculine bias. Nelson observes that this is changing, albeit slowly, under the impulse of behavioural economics and of the novel insights spilling over from neurosciences - in particular the discovery that emotions are a necessary ingredient of cognition. While welcoming the interest in interpersonal relations brought about by notions such as relational goods or by the inclusion into utility functions of terms connected with social interactions, she finds that these are still too timid departures from the traditional economic methodology. She concludes by encouraging scholars of 'happiness and interpersonal relations' to abandon with greater resolve individualistic approaches and rigid formalisation.

\section{Conclusions}

Traditionally, economics has largely disregarded personalised relationships. When the concept of social capital has broken into the fortress of economics, bringing new interest to phenomena such as trust, social norms and associational activities, the literature has emphasised the instrumental value of informal connections among the members of social groups in facilitating coordinated action.

Only recently has economics started to conceptualise the affective and communicative side of human relationships, and the intrinsic value these have for people involved. However, the empirical analysis of such elusive phenomena seemed prohibitively difficult, if not impossible. The new literature on happiness has opened new opportunities for bringing the relational side of human beings to the forefront of economic analysis. The papers presented in this special issue make an important step towards understanding relational goods and how they are linked to happiness. We believe that they will also contribute to identify the relevant questions and point out new directions for future research. 


\section{References}

Argyle M (2001) The Psychology of Happiness. Taylor \& Francis, New York

Aslam A, Corrado L (2007) No Man is an Island, the inter-personal determinants of regional well-being in Europe, Cambridge working papers in economics 0717, Faculty of Economics, University of Cambridge

Bartolini S, Bilancini E (2010) If not only GDP, what else? Using relational goods to predict the trends of subjective well-being. Int Rev Econ 57(2). doi:10.1007/s12232-010-0098-1

Baumeister RF, Leary MR (1995) The need to belong: desire for interpersonal attachments as a fundamental human motivation. Psychol Bull 117:497-529

Becchetti L, Pelloni A, Rossetti F (2008) Relational goods, sociability, and happiness. Kyklos 61(3): 343-363

Becchetti L, Trovato G, Bedoya DAL (2009a) Income, relational goods and happiness. Appl Econ 14664283. doi:10.1080/00036840802570439

Becchetti L, Ricca EG, Pelloni A (2009b) The 60es turnaround as a test on the causal relationship between sociability and happiness. Econometica working papers wp07, Econometica

Bjørnskov C (2003) The happy few: cross-country evidence on social capital and life satisfaction. Kyklos 56(1):3-16

Bjørnskov C (2007) The multiple facets of social capital. Eur J Polit Econ 22:22-40

Brennan G, Pettit P (2004) The economy of esteem. An essay on civil and political society. Oxford University Press, Oxford

Brickman P, Campbell DT (1971) Hedonic relativism and planning the good society. In: Apley MH (ed) Adaptation-level theory: a symposium. Academic Press, New York, pp 287-302

Bruni L (2008) Reciprocity, altruism and civil society. Routledge, London

Bruni L, Stanca L (2006) Income aspirations, television and happiness: evidence from the world values survey. Kyklos 59:209-225

Bruni L, Stanca L (2008) Watching alone: relational goods, television and happiness. J Econ Behav Org 65(3-4):506-528

Bünger BC (2010) The demand for relational goods: empirical evidence from the European social survey. Int Rev Econ 57(2). doi:10.1007/s12232-010-0094-5

Chase RB, Dasu S (2008) Psychology of the experience: the missing link in service science. In: Hefley B, Murphy W (eds) Service science, management and engineering: education for the 21 st Century. Springer, New York, NY, pp 35-40

Clark A, Oswald A (2002) A simple statistical method for measuring how life events affect happiness. Int J Epidemiol 31(6):1139-1144

Corneo G (2010) Nationalism, cognitive ability, and interpersonal relations. Int Rev Econ 57(2). doi: 10.1007/s12232-010-0097-2

Dasgupta P (2002) Social capital and economic performance: analytics. University of Cambridge and Beijer International Institute of Ecological Economics, Mimeo, Stockholm

Deci EL, Ryan RM (1991) A motivational approach to self: integration in personality. In: Dienstbier R (ed) Nebraska symposium on motivation: perspectives on motivation. University of Nebraska Press, Lincoln, pp 237-288

Deci RM, Ryan EL (2001) On happiness and human potentials: a review of research on hedonic and eudaimonic well-being. Ann Rev Psychol 52:141-166

DeLeire T, Kalil A (2010) Does consumption buy happiness? Evidence from the United States. Int Rev Econ 57(2). doi:10.1007/s12232-010-0093-6

Di Tella R, MacCulloch R (2006) Some uses of happiness data in economics. J Econ Perspect 20(1): $25-46$

Diwan R (2000) Relational wealth and the quality of life. J Socio-Econ 28:305-340

Dur R (2009) Gift exchange in the workplace: money or attention? J Eur Econ Assoc 7(2-3):550-560

Dur R, Roelfsema H (2010) Social exchange and common agency in organizations. J Socio-Econ 39: 55-63

Dur R, Sol J (2009) Social interaction, co-worker altruism, and incentives. IZA discussion paper 4532

Durlauf S, Ioannides Y (2010) Social interactions. Ann Rev Econ 2 (forthcoming)

Easterlin R (1974) Does economic growth improve the human lot? Some empirical evidence. In: Davis PA, Reder MW (eds) Nation and households in economic growth: essays in honor of Moses Abromowitz. Academic Press, New York, pp 89-125 
Frank R (2000) Luxury fever: money and happiness in an era of excess. Princeton University Press, Princeton

Frey BS (2008) Happiness: a revolution in economics. MIT Press, MA

Frey BS, Stutzer A (2002) Happiness and economics: how the economy and institutions affect human well-being. Princeton University Press, Princeton

Frey B, Luechinger S, Stutzer A (2004) Valuing public goods: the life satisfaction approach. CESifo working paper series no. 1158

Grootaert C, van Bastelaer T (2002) Understanding and measuring social capital: a multi-disciplinary tool for practitioners. The World Bank, Washington DC

Gui B (2005) From transactions to encounters: the joint generation of relational goods and conventional values. In: Gui B, Sugden R (eds) Economics and social interactions. Cambridge University Press, Cambridge, pp 23-51

Gui B, Sugden R (2005) Why interpersonal relations matter for economics. In: Gui B, Sugden R (eds) Economics and social interaction: accounting for interpersonal relations. Cambridge University Press, Cambridge, pp 1-22

Guiso L, Sapienza P, Zingales L (2000) The role of social capital in financial development. Am Econ Rev 94(3):526-556

Haller M, Hadler M (2006) How social relations and structures can produce happiness and unhappiness: an international comparative analysis. Soc Indic Res 75:169-216

Kahneman D (1999) Objective happiness. In: Kahneman D, Diener E, Schwartz N (eds) Well-being: foundations of hedonic psychology. Rassel Sage Foundation, New York

Kahneman D, Krueger AB, Schkade DA, Schwarz N, Stone AA (2004) A survey method for characterizing daily life experience: the day reconstruction method (DRM). Science 306:1776-1780

Kasser VM, Ryan RM (1999) The relation of psychological needs for autonomy and relatedness to health, vitality, well-being and mortality in a nursing home. J Appl Soc Psychol 29:935-954

Lane R (2001) The loss of happiness in market democracies. Yale University Press, London

Layard R (2005) Happiness: lessons from a new science. Penguin, New York, NY

Magliulo A (2010) The Austrian theory of relational goods. Int Rev Econ 57(2). doi:10.1007/ s12232-010-0100-y

Maslow AH (1962) Toward a psychology of being. D. Van Nostrand Co, Princeton, NJ

Myers DG (1999) Close relationships and quality of life. In: Kahneman D, Diener E, Schwarz N (eds) Well-being: the foundations of hedonic psychology. Russell Sage Foundation, New York, pp 376393

Nelson JA (2010) Getting past 'rational man/emotional woman': comments on research programs in happiness economics and interpersonal relations. Int Rev Econ 57(2). doi:10.1007/s12232010-0096-3

Offer A (1997) Between the gift and the market: the economy of regard. Econ Hist Rev 50(3):450-476

Powdthavee N (2008) Putting a price tag on friends, relatives, and neighbours: using surveys of lifesatisfaction to value social relationships. J Socio-Econ 37(4):1459-1480

Pugno M (2009) The Easterlin paradox and the decline of social capital: an integrated explanation. J Socio-Econ 38:590-600

Putnam R (1993) Making democracy work. Princeton University Press, Princeton

Robison LJ, Flora JL (2003) The social capital paradigm: bridging across disciplines. Am J Agric Econ 85(5):1187-1193

Robison LJ, Schmid A, Barry P (2002) The role of social capital in the industrialization of the food system. Agric Resour Econ Rev 31(1):15-24

Routledge BR, von Amsberg J (2002) Social capital and growth. J Monet Econ 50(1):167-193

Ryff CD, Singer B (2000) Interpersonal flourishing: a positive health agenda for the new millennium. Pers Soc Psychol Rev 4:30-44

Sacco PL, Vanin P, Zamagni S (2006) The Economics of Human Relationships. In: Kolm S-C, Mercier Ythier J (eds) Handbook of the Economics of Giving, Altruism and Reciprocity, Volume 1. Amsterdam, Elsevier North Holland, pp 695-730

Sonnemans J, van Dijk F, van Winden F (2006) On the dynamics of social ties structures in groups. J Econ Psychol 27(2):187-204

Stanca L (2009) With or without you: measuring the quality of relational life throughout the world. J Socio-Econ 38:834-842

Sugden R (2002) Beyond sympathy and empathy: Adam Smith's concept of fellow-feeling. Econ Philos 18(1):63-87 
Sugden R (2005a) Correspondence of Sentiments: An Explanation of the Pleasure of Social Interaction. In: Bruni L, Porta P (eds) Economics and Happiness: Framing the Analysis. Oxford University Press, Oxford, pp 91-115

Sugden Robert (2005b) Fellow-Feeling, in Gui B. and Sugden R., Economics and Social Interaction: Accounting for Interpersonal Relations. Cambridge, Cambridge University Press, pp 52-75

Uhlaner C (1989) Relational goods and participation: incorporating sociability into a theory of rational action. Public Choice 62:253-285

Van Praag B, Ferrer-i-Carbonell A (2004) Happiness quantified: a satisfaction calculus approach. Oxford University Press, Oxford

Van Winden F, Stallen M, Ridderinkhof KR (2008) On the nature, modeling, and neural bases of social ties. In: DE Houser, KA McCabe (eds) Neuroeconomics, vol 20. Advances in Health Economics and Health Services Research. Emerald Insight Publishing, London, pp. 125-159

Zappa P, Zavarrone E (2010) Social interaction and volunteer satisfaction: an exploratory study in primary healthcare. Int Rev Econ 57(2). doi:10.1007/s12232-010-0095-4 